\title{
PHYLOGENETIC ANALYSIS OF THE SWINE LEUKOCYTE ANTIGEN-6 GENE GENERATED FROM SPLEENTISSUE OF KOREAN NATIVE PIG
}

\author{
Jaeyoung Kim, Hyojun Park, Yoonchung Choi and Hoyoung Chung \\ National Institute of Animal Science, Animal Genomics Bioinformatics Division, Suwon, 441706 Korea
}

Received 2013-10-22; Received 2014-02-15; Accepted 2014-02-22

\begin{abstract}
This study was aimed to search genetic variants, to investigate phylogenetic relationships between pig breeds and to provide basic genetic information of Korean Native Pigs (KNP) using the variations of the Swine Leukocyte Antigen-6 (SLA-6) gene. Cloning of the Swine Leukocyte Antigen (SLA)-6 gene in the MHC non-classical region was performed with spleen tissues of Korean Native Pigs (KNP). Sequencing analysis identified 10 genetic variants positioned at nucleotides $108(\mathrm{~T}>\mathrm{C}), 251(\mathrm{G}>\mathrm{A}), 324(\mathrm{C}>\mathrm{A}), 460$ $(\mathrm{T}>\mathrm{C}), 556(\mathrm{~T}>\mathrm{C}), 559(\mathrm{~A}>\mathrm{G}), 598(\mathrm{G}>\mathrm{A}), 665(\mathrm{~T}>\mathrm{C}), 920(\mathrm{G}>\mathrm{A})$ and $1,115(\mathrm{G}>\mathrm{A})$. The identified sequences were submitted into GenBank with accession numbers (DQ992502-10 and DQ976363) according to the specified locations of each SNP. Clustering analysis revealed that KNP was formed to a major group, showing close genetic relationships with SLA-6*0105, SLA-6*01w01 and SLA-6*w02sa01 alleles except DQ992503. KNP showed the low nucleotide diversity with significant differences of the ratio of ti/tv (transition/transversion) compared with other breeds. The identified variants of the SLA-6 gene are useful information to differentiate phylogenetic relationships between KNP and other pig breeds. The unique results of the SLA-6 SNPs of KNP will serve as reference study for further analyses of gene fixations in evolution studies.
\end{abstract}

Keywords: SLA-6, Genetic Relationship, Korean Native Pig, Polymorphism, SNP

\section{INTRODUCTION}

The Swine Leukocyte Antigen (SLA), which is expressed on the surface of most nucleated cells and recognized by $\mathrm{CD} 8+$ cells, has been issued in transplantation studies with the precise SLA genotypes and alleles (Ando et al., 2003; Barbosa et al., 2004; Chardon et al., 2001). The MHC region containing huge mutation sites is able to characterize individual differences using several allelic variations due to more than 1500 alleles in human (Giovambattista et al., 2001) while limited numbers of allelic variations have been characterized in swine (Crew et al., 2004; Ehrlich et al., 1987). The genetic information of SLA has been actively studied to understand immune systems and to identify the influence of the SLA genes on immune responses, organ transplantation and disease resistances (Kim et al., 2005). According to the question in the human medical issues for understanding mechanisms of immune responses, lots of efforts to solve the questions regarding difficulties in transplantation have been applied with porcine tissues that were believed to be candidate organ materials. Meanwhile, as a candidate experimental animal, the transplantation research seeks availability of Korean Native Pigs (KNP) that appear relatively small body sizes comparing with other breeds even though very limited genetic information for the characterization of KNP is available (Kim et al., 2006; Chung and Yoon, 2008; Chung et al., 2011). Therefore, it is necessary to characterize genetic variations in the SLA-6 genes for KNP that has been maintained as a closed population for a long-period time.

SLA-6 is in the SLA non-classical region located in pig chromosome 7 (Mallard et al., 1989). Even though exact functions of the non-classical SLA genes (SLA-6, of Animal Science, Animal Genomics Bioinformatics Division, Suwon, 441706 Korea Tel: +82-031-290-1596, Fax: +82-031-290-1752 
-7 and -8) have not been determined, it is similarly predicted to genes in the classical SLA I region. As glycoproteins with the potential of binding peptides, a study (Martens et al., 2003) reported that swine showed negative homologous to the SLA-6 gene for human and mice while expression of the SLA-6 mRNA transcripts in a variety of tissues presented similar patterns with HLA-E (Park et al., 2010). A previous study reported that SLA-6 comprising 270 amino acid residues expressed as monomorphic proteins (Chardon et al., 2001). In addition, it is really important to confirm expression patterns according to the genetic variants and to verify polymorphisms in KNP that has never been analyzed regarding SLA-6. Collecting genetic variants in coding regions of SLA-6 should be an initial step to characterize variability and identify the SLA-6 alleles for KNP. Thus, this study was aimed to verify SLA-6 and provide genetic and phylogenetic information of KNP for further studies.

\section{MATERIALS AND METHODS}

\subsection{Experimental Animals}

This analysis was designed to verify genetic variants of the coding regions of SLA- 6 and to find genetic differences with previously defined Korean pigs and other pig breeds. KNP has been maintained to preserve genetic materials at National Institute of Animal Science (NIAS) in Korea and a total of $30 \mathrm{KNP}$ aged 30 weeks from different sired lines were randomly selected. The pedigree analysis confirmed no significant genetic relationships, showing less than 0.01 inbreeding coefficients. The animals registered in the national database had standard breeding programs under the restricted guidelines provided by NIAS and the animals were fed up with standardized diets with the NRC (2000). After Slaughter at the facility of NIAS, the harvested spleen tissues $(10 \mathrm{~g})$ were cut into small sections (2-3 mm cubes) and placed into a $-70^{\circ} \mathrm{C}$ deep freezer until uses.

A total of 28 Yorkshire pigs, which had no particular genetic relationships according to the pedigree from NIAS, were used for the genotyping of microsatellite loci to compare genetic variability against KNP. The pedigree analysis ascertained that Yorkshire pigs having less than 0.01 of inbreeding coefficients were selected from sire lines at NIAS. Approximately, $5 \mathrm{~mL}$ of blood samples was taken from the jugular vein after postweaning tests of 150 days. This experiment involving procedures and animals was approved by the ethics and welfare committee of NIAS.

\subsection{Analysis of Microsatellite Loci}

Even though the pedigree analysis described no significant genetic relationships among $30 \mathrm{KNP}$ animals that were offspring of frequently used sire lines, small numbers of animals open give biased results because of extremely low genetic variability. Therefore, a total of 19 microsatellite loci were used to verify whether the selected population of KNP can have enough genetic variability or not. The used 18 Micro Satellite loci (MS), which were distributed in all over the pig Chromosomes (Ch), were presented in Table 1. For the optimal PCR conditions, a gradient PCR was performed with $2 \mathrm{uL}$ of $10 \mathrm{X}$ reaction buffer $(10 \mathrm{mM}$ Tris, pH 8.3, $50 \mathrm{mM} \mathrm{KCl,} \mathrm{0.1 \%} \mathrm{Triton} \mathrm{X-100,} 1.5 \mathrm{mM}$ $\mathrm{MgCl}_{2}$ ), $25 \mathrm{mM}$ of dNTP, 10 pmol of each primer, 50 ng of genomic DNA and 2 units of Taq DNA polymerase (Gibco BRL, USA) in a final volume of 20 uL (MJ Research, PT-200, Watertown, MA). The genotyping was conducted using an ABI3730XL Genetic Analyzer (Applied Biosystems, USA).

\subsection{Primers for Polymerase Chain Reaction}

Primer selections for SLA-6, which consisted of 7 exons in 1,087 bp length, were based on the swine coding sequence (a GenBank accession no. AF464007) with options of $60 \% \mathrm{GC}$ content and 1,400 bp of length. The forward and reverse primers were AAACT CAGAT CCGCC ACAGA (at nucleotide positions 13-32) and TTCAC ACAGC TTTAT TGAAG CAA (at nucleotide positions 1,385-1,407), respectively. An internal forward primer positioned at 431 to 450 (ATTGG CAACC ACAAC CATAG) was also used to confirm correct amplification products because high sequence similarities between genes around the SLA classical and non-classical regions.

\subsection{1. cDNA Synthesis}

Homogenization was performed with $2 \mathrm{~g}$ of tissue samples in $1 \mathrm{ml}$ of Trizol (Sigma, USA) at liquid nitrogen. The total RNA was extracted from $30 \mathrm{KNP}$ pigs by using a kit (RNeasy Midi kit, Qiagen) followed by manufacturer's guidelines and the total RNA was in 50 $\mathrm{uL}$ of RNase-free water. The first strand was synthesized by oligo dt primers with $5 \mathrm{X}$ First-Strand Buffer, 0.1M DTT, RNasin and SuperScript ${ }^{\mathrm{TM}}$ III Reverse Transcriptase (Invitrogen) standing for $5 \mathrm{~min}$ at $25^{\circ} \mathrm{C}, 2$ $\mathrm{h}$ at $50^{\circ} \mathrm{C}$ and $15 \mathrm{~min}$ at $70^{\circ} \mathrm{C}$. 
Jaeyoung Kim et al. / American Journal of Animal and Veterinary Sciences 9 (1): 56-64, 2014

Table 1. Number of alleles, expected heterozygosity and gene diversity for the microsatellite loci in pig populations

KNP (30)

\begin{tabular}{|c|c|c|c|c|c|c|c|c|c|c|c|c|c|c|c|}
\hline Loci & $\mathrm{A}^{1}$ & $\mathrm{He}^{2}$ & $\mathrm{GD}^{3}$ & Loci & A & $\mathrm{He}$ & GD & Loci & A & $\mathrm{He}$ & GD & Loci & A & $\mathrm{He}$ & GD \\
\hline S0002 & 2 & 0.443 & 0.444 & S0227 & 2.0 & 0.501 & 0.503 & S0002 & 3 & 0.574 & 0.567 & S0227 & 4.0 & 0.587 & 0.588 \\
\hline S0005 & 5 & 0.559 & 0.558 & S0228 & 7.0 & 0.847 & 0.850 & S0005 & 7 & 0.833 & 0.834 & S0228 & 6.0 & 0.773 & 0.702 \\
\hline S0026 & 6 & 0.793 & 0.793 & S0386 & 5.0 & 0.726 & 0.729 & S0026 & 2 & 0.503 & 0.500 & S0386 & 4.0 & 0.678 & 0.688 \\
\hline S0068 & 3 & 0.503 & 0.502 & S0355 & 5.0 & 0.730 & 0.733 & S0068 & 2 & 0.439 & 0.438 & S0355 & 7.0 & 0.788 & 0.786 \\
\hline S0090 & 4 & 0.703 & 0.707 & SW24 & 4.0 & 0.627 & 0.639 & S0090 & 3 & 0.568 & 0.563 & SW24 & 3.0 & 0.472 & 0.539 \\
\hline S0101 & 3 & 0.384 & 0.384 & SW787 & 4.0 & 0.595 & 0.596 & S0101 & 2 & 0.225 & 0.229 & SW787 & 4.0 & 0.439 & 0.438 \\
\hline S0155 & 5 & 0.397 & 0.399 & SW857 & 4.0 & 0.703 & 0.706 & S0155 & 2 & 0.284 & 0.283 & SW857 & 6.0 & 0.757 & 0.756 \\
\hline S0218 & 4 & 0.636 & 0.643 & SW911 & 4.0 & 0.650 & 0.649 & S0218 & 3 & 0.457 & 0.462 & SW911 & 4.0 & 0.562 & 0.563 \\
\hline S0225 & 2 & 0.089 & 0.089 & SW951 & 3.0 & 0.513 & 0.508 & S0225 & 2 & 0.254 & 0.255 & SW951 & 2.0 & 0.503 & 0.502 \\
\hline S0226 & 2 & 0.406 & 0.405 & Mean & 3.9 & 0.491 & 0.570 & S0226 & 3 & 0.551 & 0.550 & Mean & 3.6 & 0.469 & 0.543 \\
\hline
\end{tabular}

${ }^{\mathrm{T}}$ Number of allele; ${ }^{2}$ Expected Heterozygosity; ${ }^{3}$ Gene diversity per locus parentheses are numbers of individuals genotyped in this analysis

To amplify cDNA segments, $2 \mathrm{uL}$ of $10 \mathrm{X}$ reaction buffer (10 mM Tris, pH 8.3, 50 mM KCL, 0.1\% Triton X-100, $1.5 \mathrm{mM} \mathrm{MgCl}_{2}$ ), $10 \mathrm{mM} \mathrm{dNTP}, 10 \mathrm{pM}$ of each primer, $30 \mathrm{ng}$ of cDNA and 2 units of Taq DNA polymerase (Gibco BRL, NY) in a final volume of $20 \mathrm{uL}$ were used. After denaturation at $95^{\circ} \mathrm{C}$ for $3 \mathrm{~min}$, a total of 35 cycles were adapted for denaturation at $94^{\circ} \mathrm{C} / 1 \mathrm{~min}$, annealing at $61^{\circ} \mathrm{C} / 1 \mathrm{~min}$ and polymerization at $72^{\circ} \mathrm{C} / 2 \mathrm{~min}$.

\subsection{Sequencing Analysis}

Amplified PCR fragments of SLA-6 showing approximately $1,395 \mathrm{bp}$ were identified and purified from $1.2 \%$ agarose gels using the Nucleotrap gel purification system (Clontech, CA). Each fragment from individuals was inserted into a pGEM T-easy vector at $4{ }^{\circ} \mathrm{C}$ for overnight and transformed into the DH10B competent cells (Promega, WI). The plasmid was purified using a Mini-plasmid prep kit (Qiagen, $\mathrm{CA}$ ) and sequencing was conducted with an ABI3730XL Genetic Analyzer using T7 and SP6 universal primers. PCR and sequencing reactions were duplicated to minimize base-calling errors. A total of 460 clones from $30 \mathrm{KNPs}$ were sequenced to determine genetic variants in the coding regions.

\subsection{Statistical Analysis}

The GENEPOP (Version 3.3) package calculated the number of alleles, allele frequencies, expected heterozygosity and gene diversity. Individual sequences of cDNA were aligned by the Seqman program and clustered by the Megalign program of DNAstar version 6.1. The identified sequences containing SNP were submitted into GenBank with accession numbers and compared with previously submitted SLA-6 alleles from the Immuno Polymorphism Database (IPD). A phylogenetic tree was constructed with a DNAdist option (MEGA version 5.2) for identifying genetic distances between the SLA- 6 alleles. A total of 16 unique alleles of the SLA-6 gene from GenBank with accession numbers were used to characterize phylogenetic relationships among alleles as well as breeds including KNP. Statistical summaries for nucleotide diversity, substitutions and frequencies were described using ARLEQUIN version 2.0.

\section{RESULTS}

\subsection{Analysis of Repeat Units}

The genetic variability was tested with 19 microsatellite loci for 58 individuals from KNP and Yorkshire pigs and numbers of alleles, expected heterozygosity and genetic diversity were estimated (Table 1). The highest number of alleles was 7 in MS markers (S0228, S0005 and S0355) and the lowest number of alleles was 2 in several markers. Overall average number of alleles for KNP was higher (3.9) than Yorkshire (3.6), caused by either high genetic variability of KNP than Yorkshire or different numbers of individuals that had significant different genetic backgrounds. The same patterns of the high average gene diversity and heterozygosity of KNP comparing with Yorkshire were observed. The analysis estimated the average gene diversity of KNP (0.492) that was lower than Yorkshire (0.648), but the results were similar to the report $(0.489)$ of natural populations (Rahman et al., 2006). 


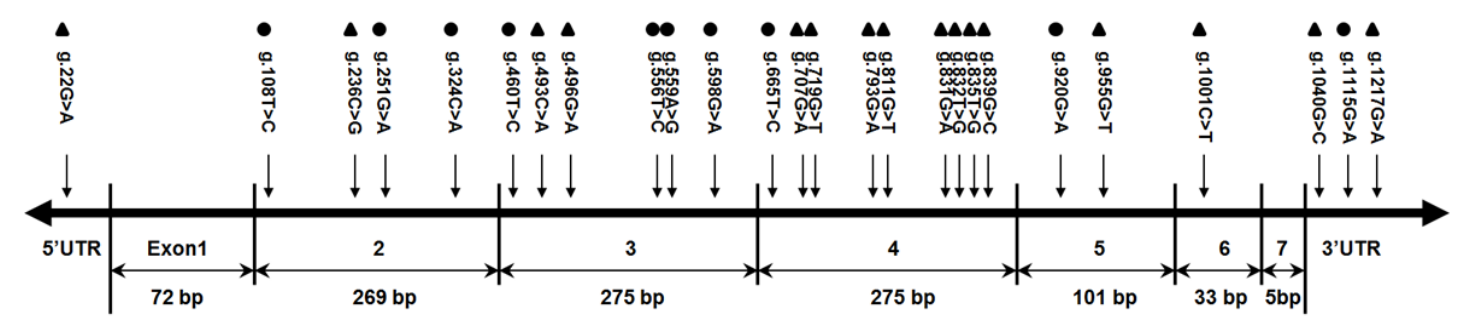

Fig. 1. A map has been constructed with the identified SNP for the SLA-6 gene showing nucleotide substitutions. Exons and UTRs were presented with the length of sequences. The genetic variations in the SLA- 6 gene were confirmed using 16 previously defined SLA-6 alleles (triangle) as well as 10 identified sequences for KNP (circle) in this study. The nucleotide positions were based on a GenBank accession number (DQ992510) that was generated from this study.

Table 2. Genetic variations of the SLA-6 gene in KNP

\begin{tabular}{|c|c|c|c|c|c|c|}
\hline \multirow[b]{2}{*}{$\mathrm{SNP}^{1}$} & \multicolumn{3}{|l|}{ Substitution } & \multirow[b]{2}{*}{$\begin{array}{l}\text { Minor } \\
\text { allele frequency }\end{array}$} & \multirow[b]{2}{*}{$\begin{array}{l}\text { Coding } \\
\text { region }\end{array}$} & \multirow[b]{2}{*}{$\begin{array}{l}\text { GenBank } \\
\text { accession Number }^{3}\end{array}$} \\
\hline & Nucleotide & Amin & ability $^{2}$ & & & \\
\hline $\begin{array}{l}\text { g.108T }>C \\
\text {. }\end{array}$ & $\mathrm{T}>\mathrm{C}$ & L-P & 0.047 & 0.008 & 2 & DQ992505 \\
\hline g. $251 \mathrm{G}>\mathrm{A}$ & $\mathrm{G}>\mathrm{A}$ & G-S & 0.061 & 0.011 & 2 & DQ992503 \\
\hline g. $324 C>A$ & $\mathrm{C}>\mathrm{A}$ & $\mathrm{P}-\mathrm{Q}$ & 0.433 & 0.156 & 2 & DQ992506 \\
\hline g. $460 \mathrm{~T}>\mathrm{C}$ & $\mathrm{T}>\mathrm{C}$ & - & 0.084 & 0.016 & 3 & DQ992504 \\
\hline g. $556 \mathrm{~T}>\mathrm{C}$ & $\mathrm{T}>\mathrm{C}$ & - & 0.105 & 0.022 & 3 & DQ992509 \\
\hline g. $559 A>G$ & $\mathrm{~A}>\mathrm{G}$ & - & 0.061 & 0.011 & 3 & DQ992502 \\
\hline g. $598 \mathrm{G}>\mathrm{A}$ & $\mathrm{G}>\mathrm{A}$ & - & 0.792 & 0.135 & 3 & DQ976363 \\
\hline g. $665 \mathrm{~T}>\mathrm{C}$ & $\mathrm{T}>\mathrm{C}$ & C-R & 0.072 & 0.014 & 4 & DQ992507 \\
\hline g. $920 \mathrm{G}>\mathrm{A}$ & $\mathrm{G}>\mathrm{A}$ & V-M & 0.061 & 0.011 & 5 & DQ992503 \\
\hline g. $1115 \mathrm{~A}>\mathrm{G}$ & $A>G$ & - & 0.034 & 0.005 & $3^{\prime}$ & UTRDQ992510 \\
\hline
\end{tabular}

${ }^{1}$ The locations were based on DQ992510; ${ }^{2}$ The variability was estimated by the entropy options that measure amount of variation in a column in an alignment; ${ }^{3}$ The identified sequences according to the genetic variants were submitted into GenBank with accession numbers

The MS markers have been used to ensure that the KNP population is not much inbreed and isolated against standardized pig populations. If the result of MS analysis shows significantly low genetic variability in KNP, the selected animals may not be a representative for KNP. From the results, a critical opinion that genetic variability of KNP should be greater than Yorkshire meets the expected criteria that the selected individuals of KNP have enough genetic variability to search Single Nucleotide Polymorphisms (SNP) of SLA-6.

\section{2. cDNA Analysis}

Electrophoretic separations detected sizes of the isolated cDNA as the full-length SLA-6 genes varying 950 to $1430 \mathrm{bp}$. Due to the variation of sequence lengths, amplified products less than 1,000 bp, which occupied approximately $5 \%$ in this analysis, were compared with previously deposited sequences in GenBank. After verification of sequences, the fragment was assumed for containing missing parts in coding regions and therefore, the sequence length less than $1,000 \mathrm{bp}$ was eliminated for further analyses. Successfully amplified cDNA of SLA-6 was confirmed as 1,395 bp that contained the whole coding regions with 5' and 3' UTRs. An internal primer was used to verify SLA-6 because genes in the SLA regions showed high sequence similarities that may interrupt amplifications. The sequence alignments verified that coding regions were started from a nucleotide position 29 and ended at 1,138 based on sequences from a GenBank accession number (DQ992510) generated from KNP in this study. Nucleotide sequences in coding regions for all KNP were compared to identify genetic variants. As shown in Fig. 1, a total of $26 \mathrm{SNP}$, which contained previously identified 16 SNP according to the characterization of the SLA- 6 alleles from GenBank, have been identified and the newly detected 10 SNP in this study using KNP were presented with a shape of circles. The identified sequences were submitted into GenBank with accession numbers according to the SNP positions (Table 2).

The present findings are in a good agreement with the report that a stop codon in exon number 7 was observed and resulted in total 270 amino acids (Charon, 2001). The sequence analysis observed amino acid substitutions in DQ992503 (G>S and $\mathrm{V}>\mathrm{M})$, DQ992505 (L>P), DQ992506 and DQ992508 (P>Q) and DQ992507 $(\mathrm{C}>\mathrm{R})$. Overall, exon numbers 2 and 3 occupied more than $70 \%$ of genetic variants. The analysis confirmed 4 
SNP (nucleotide positions 22, 1,040, 1,115 and 1,217) located in both 5' and 3' UTR regions. The sequence comparisons identified major differences between KNP and SLA-6*0105 (Meishan), showing variants at nucleotide positions g.936T $>\mathrm{G}$ and g.1096G $>\mathrm{A}$ that were observed in Meishan only. Minor Allele Frequencies (MAF) were calculated and g.324C>A was revealed the highest allele frequency (0.156). Even though, MAF of g.598G $>$ A was lower than g. 324C $>$ A, the variability of g.598G $>$ A revealed the highest value (0.792) compared with g.324C>A (0.433). Other than these 2 SNPs, the rest of SNPs showed extremely low MAF values.

\subsection{Genetic Diversity}

To investigate genetic distances between KNP and 16 representative SLA-6 alleles (Table 3), a phylogenetic tree was constructed (Fig. 2). A close genetic distance between the identified KNP in this study and previously defined 3 alleles (SLA-6*0101, SLA-6*0102 and SLA-6*w04jh01) using Korean pigs has been hypothetically expected due to the same native breed. However, the most obvious point was that the identified sequences of KNP showed differences in a varying degree from the previously identified SLA6*0101 allele (DQ883215) that presented significant genetic similarities with Large White (AY463540). In addition, all KNP individuals were clustered into a major group except DQ992503 that was slightly departed from KNP and the results were caused by SNP located at nucleotide positions g.324C $>$ A and g.598G>A. Significantly high sequence similarities have been observed among pig populations such as KNP, Meishan (SLA-6*0105), NIH (SLA-6*0102 and SLA-6*w02sa01) and western (SLA-6*01w01) breeds. In contrast, other SLA-6 alleles (SLA-6*0104 and SLA-6*0103) of the Meishan breed did not show close genetic distances with KNP.

The low overall polymorphic information (2.311) and nucleotide diversities (0.002) were estimated in KNP against Meishan, previously identified Korean pigs (KOR) and OUT consisted of Yucatan, NIH and LW (Table 4). The results may characterize specificities of genetic constitutions of KNP that show a little degree of the inbreeding status. For the convenience of further evidence, the nucleotide substitutions by transitions and transversions were revealed that KNP had the highest ti and the lowest tv, resulting in a significantly high ti/tv ratio (9.000) compared with others (average 0.578). The results imply that KNP may be a little away from the major evolutionary pathways comparing with other pig populations.

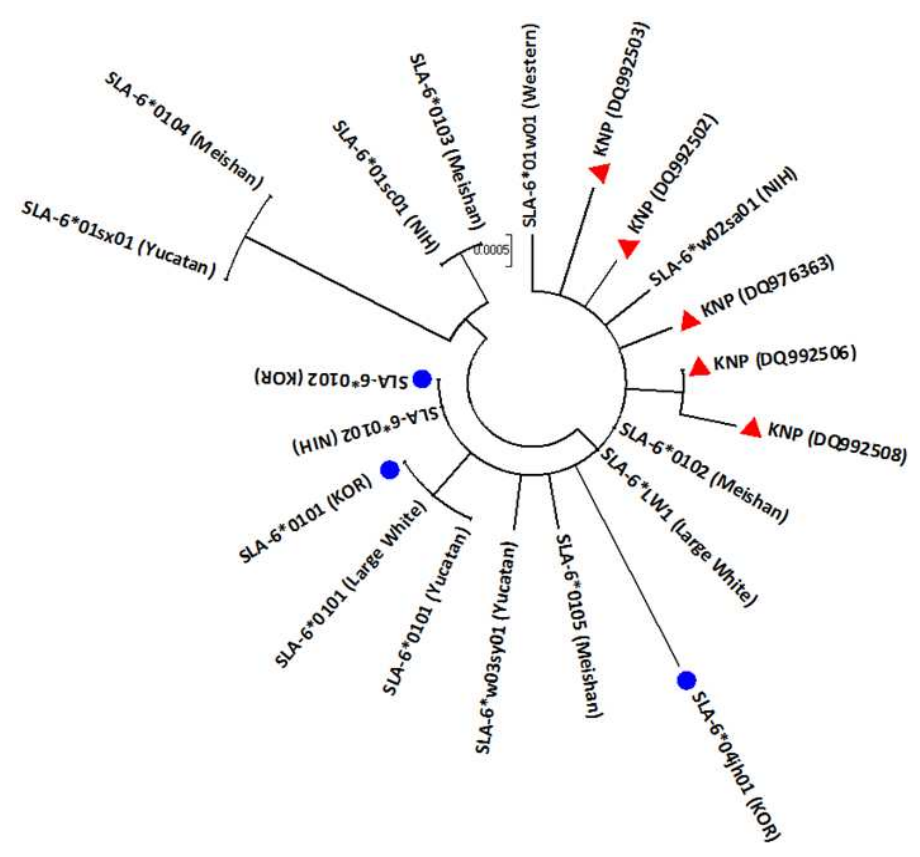

Fig. 2. The phylogenetic relationships of the SLA-6 sequences among Korean Native Pigs (KNP) and 16 SLA-6 segments (complete cDNA sequences from GenBank representing the SLA-6 alleles). The phylogenetic tree was constructed with DNADist in Bioedit program version 7.0.1. Accession numbers (DQ992502-DQ992510 and DQ976363) represented KNP (triangles with red color) in this study and KOR represented previously defined Korean pigs (circles with blue color). 
Jaeyoung Kim et al. / American Journal of Animal and Veterinary Sciences 9 (1): 56-64, 2014

Table 3. The SLA-6 alleles, breeds and accession numbers that used to determine genetic distances using SNP

\begin{tabular}{|c|c|c|c|c|c|}
\hline Group & Allele & Previous designation & Breed & Accession number & Reference \\
\hline \multirow[t]{14}{*}{ SLA-6*01 } & 0101 & $\mathrm{z}$ & Yucatan & AF464006 & Martens et al., 2003 \\
\hline & & & Large White & AY463540 & Crew et al., 2004 \\
\hline & 0101 & & KNP & DQ883215 & GenBank \\
\hline & 0102 & & $\mathrm{NIH}$ & AF464020 & Martens et al., 2003 \\
\hline & & LW1 & Large White & AY247772 & GenBank \\
\hline & 0102 & & Meishan & EU432054 & GenBank \\
\hline & 0102 & $\mathrm{a}$ & KNP & DQ883216 & GenBank \\
\hline & 0103 & & Meishan & EU432055 & GenBank \\
\hline & 0104 & & Meishan & EU432056 & GenBank \\
\hline & 0105 & & Meishan & EU432057 & GenBank \\
\hline & W04jh01 & & KNP & DQ883214 & GenBank \\
\hline & 01we01 & We1 & Western & AY247771 & GenBank \\
\hline & $01 \mathrm{sc} 01$ & $\mathrm{c}$ & $\mathrm{NIH}$ & AY459304 & Martens et al., 2003 \\
\hline & $01 \mathrm{sx} 01$ & $\mathrm{x}$ & Yucatan & AF464008 & Martens et al., 2003 \\
\hline SLA-6*w02 & W02sa01 & $\mathrm{a}$ & $\mathrm{NIH}$ & AF464019 & Martens et al., 2003 \\
\hline SLA-6*w03 & W03sy01 & $\mathrm{y}$ & Yucatan & AF464007 & Martens et al., 2003 \\
\hline
\end{tabular}

Table 4. Number of polymorphic sites, nucleotide diversity, transition/transversion ratio and compositions of nucleotides

\begin{tabular}{|c|c|c|c|c|c|c|c|}
\hline \multirow[b]{3}{*}{ Breed $^{1}$} & \multirow[b]{3}{*}{$\mathrm{N}$} & \multicolumn{3}{|c|}{ Polymorphic region } & \multirow{2}{*}{\multicolumn{3}{|c|}{ Count }} \\
\hline & & \multirow{2}{*}{$\begin{array}{l}\text { Polymorphic } \\
\text { information }\end{array}$} & \multirow[b]{2}{*}{ Nucleotide diversity } & \multirow[b]{2}{*}{$\mathrm{ti} / \mathrm{tv}$} & & & \\
\hline & & & & & $\mathrm{ti}^{2}$ & $\mathrm{tv}^{3}$ & SNP \\
\hline$\overline{\text { OUT }}$ & 9.00 & 2.556 & $0.0023 \pm 0.001$ & 0.667 & 4.00 & 6.00 & 10 \\
\hline KOR & 3.00 & 3.333 & $0.0029 \pm 0.001$ & 0.667 & 2.00 & 3.00 & 5 \\
\hline KNP & 30.00 & 2.311 & $0.0021 \pm 0.001$ & 9.000 & 9.00 & 1.00 & 10 \\
\hline MES & 4.00 & 3.607 & $0.0033 \pm 0.001$ & 0.400 & 2.00 & 5.00 & 7 \\
\hline Mean & 11.50 & 2.952 & $0.0026 \pm 0.001$ & 1.133 & 4.25 & 3.75 & 8 \\
\hline
\end{tabular}

${ }^{1}$ OUT: All breeds except Korean Native Pig (KNP) and Meishan (MES) breeds; KOR: Previously defined Korean pigs; ${ }^{2}$ ti: Transition (T/C and A/G); ${ }^{3} \mathrm{Tv}$ : Transversion (A/T, T/G, C/G and A/C)

\section{DISCUSSION}

\subsection{Microsatellite Loci}

As a study (Takezaki and Nei, 1996) determined that the average heterozygosity was ranged from 0.5 to 0.8 in natural populations to be useful markers for measuring genetic variations, the present study marginally tended to agree the ranges even though the value was slightly low (0.491). If there was a high selection pressure in KNP for a long-period time to produce well-known favorite features of native pigs, low levels of heterozygosity and gene diversity would be expected. Even though ranges of the expected heterozygosity in KNP (0.491) were greater than that of Yorkshire (0.469), the result may not be directly referred to a natural population for KNP. In fact, this is somewhat expected because KNP has not been actually selected for commercial purposes due to no popularity in markets. In addition, the average weight at days 150 was significantly lower than any other pig breeds and therefore, traits of average daily gain and feed efficiency were not compatible against the major pig breeds such as Yorkshire, Landrace, Duroc and so on. Therefore, it is technically difficult to describe KNP as a natural population that means inbreeding coefficients should be higher than expected.

As the hypothetical idea assumed that KNP was in a significantly high inbreeding status due to managements of populations with limited numbers of sires that were maintained for preservation purposes, the low genetic diversity of KNP was eventually expected. In contrast, the results showing high genetic diversity compared with Yorkshire implied that significantly biased mating systems have not been adapted in KNP with small proportions of sires. The results may also assume that the genetic variability of KNP is placed in a marginal and natural breeding stage. The result of heterozygosity was also agreed with other studies that have used native pig breeds showing ranges of heterozygosity from 0.49 to 0.70 (Rothschild et al., 1984; Shigenari et al., 2004; Smith et al., 2004; Ednaldo et al., 2012). Consequently, 
the gene diversity of KNP is not significantly departed from Yorkshire and therefore, the selected KNP is to be an appropriate population as a representative breed regarding searching SNPs in SLA-6.

\subsection{Sequence Analysis}

Genetic variants of SLA-6 derived from spleen tissues of KNP may be unique characteristics and therefore, the SNP can be used to develop an inbreed line and to differentiate pig breeds. Even though there were not enough reports for SNP due to limited polymorphisms in SLA-6, a study (Smith et al., 2004) found 2 SNPs at nucleotide positions g.465G>A (AF464019) and g.679G>A (AF464007), but these SNPs were not detected in this analysis. Alignments identifying SNPs between KNP and other SLA-6 alleles detected high sequence similarities, showing only differences at 10 nucleotide positions $(108,251,324,460,556,559$, $598,665,920$ and 1115) that may account for the major differentiation of the SLA-6 alleles. In addition, the identified SNPs, which were not shown in the previously determined SLA-6 alleles from GenBank, may aid to characterize breed specificities as well as allelic types of individuals. An earlier study mentioned that SLA-6 has a stop codon in exon 7 leading to a matured SLA-6 protein comprising only 270 Amino Acid (AA) residues rather than 274 AA (Chardon et al., 2001) and the present study confirmed 270 AA.

The ratio of $\mathrm{ti} / \mathrm{tv}$, which is a parameter for phylogenetic estimations, intended to reflect the fact that nucleotide substitutions are not all equally likely between pig breeds. The substitution presented nucleotide diversities according to the transitions $(\mathrm{T}>\mathrm{C}$ and $\mathrm{A}>\mathrm{G}$ ) and transversions $(\mathrm{A}>\mathrm{T}, \mathrm{T}>\mathrm{G}, \mathrm{C}>\mathrm{G}$ and $\mathrm{A}>\mathrm{C}$ ) while performing a comparative analysis of sequences between populations. In general, a ratio of ti $>$ tv ranges from 1 to 2 because transversions $(A>C$ and $T>G)$ are 3 times less frequency in the animal genome (Keller et al., 2007). The present study compromises similar results except KNP that showed extremely high frequencies of transitions that leads the high ratio of ti/tv (an average 9.0). The results are caused by more substitutions of $\mathrm{T} / \mathrm{G}$ and $\mathrm{A} / \mathrm{C}$ while low transversions of $\mathrm{A} / \mathrm{T}$ and $\mathrm{C} / \mathrm{G}$ are presented. Therefore, the results imply that KNP holds significantly different aspects of genetic diversities in terms of general patterns for genetic segregations of genes from the evolutional pathways. In addition, the mutation sites in this analysis are unique positions that can identify breed specificity.

In fact, SNPs are significantly used to determine the SLA haplotypes that can characterize population resources when trying to identify indigenous animal populations. Finding new SNPs in the SLA region, therefore, may give us valuable information to decide haplotypes, as well as to present distinguishable diversities of animal populations. The newly identified SNPs in this study can provide useful genetic information to phylogenetic studies and the SNPs in KNP would have maximal relevance to explain pig diversities as well as to determine genetic characteristics of individual animals.

\subsection{Phylogenetic Analysis}

It is assumed that population sizes of KNP were extremely small over the past decades due to a shortage of commercial popularity causing dramatic decreases numbers of animals and allele frequencies. A limited portion of animals was selected and distributed either naturally or artificially and therefore, the low allelic distribution showing low heterozygosity would be expected. However, the analysis revealed a relatively high heterozygosity when KNP has been compulsively assigned to SLA-6*w11jh01 and SLA-6*w11jh02 alleles, showing approximately $57 \%$ of heterozygosity that was greater than that of reports $(51 \%)$ using the SLADQ1B gene (Takezaki and Nei, 1996). The heterozygosity of KNP is still low, comparing with naturally managed populations; for example, the heterozygosity of the BoLADRB3 gene has been reported as 47 to $93 \%$ using indigenous animals (Yang et al., 2003; Zhang et al., 2003). It is, therefore, kindly expected that allele frequencies of SLA-6 for KNP are slightly skewed and fixed in a favorite way of selections. In fact, most domesticated pig breeds tend to be genetically uniformed as a result of high levels of gene flow among populations and artificial selections with highly reproductive individuals. As a matter of fact, KNP has been preserved for a long-period time without introducing out breeds and this is a critical point to maintain KNP as a pure line. In addition, it is a beneficial aspect for using closed populations with significantly high inbreeding coefficients to make an experimental population with reducing potential variations and increasing gene fixations. Most domestic animals are also highly selected for economic important traits such as average daily gain or meat production and the directional selection may reduce genetic diversity as well as genetic variability. The high levels of artificial selection through the intensive uses of elite sires can assist increases of reproduction rates with reducing the 
effective population size. However, this is not the critical point to explain differences of genetic diversity with limited genetic information for the SLA-6 genotypes and alleles because KNP has not been intensively selected. There is no significant evidence that KNP has been highly inbred based on several values of genetic variability. Furthermore, if heterozygous markers of SLA-6 in KNP are lower than other domestic populations, the selected individuals with the SLA genotypes and alleles may be helpful to maintain pig populations for specific purposes in animal breeding areas. The low allelic diversity of the SLA genes can be used for management of KNP in order to increase population fitness. However, a current situation of genetic variability of KNP is too wide to use as a highly standardized population and therefore, KNP should be maintained to reduce and standardize genetic variability for further uses in model animals.

\section{CONCLUSION}

According to the identified genetic information for sequences and alleles of the SLA-6 gene, comparisons and phylogenetic analyses confirmed that KNPs in this analysis were significantly differed from the previously reported Korean pigs (SLA-6*0101, SLA$6 * 0102$ and SLA- $6 * 04 \mathrm{jh} 01)$ and other pig breeds. Two genetic variants (g.324C>A and g.598G >A) out of 10 should be informative according to the MAF that were 0.156 and 0.135 , respectively. Therefore, genetic variants of the SLA-6 gene in the present report provide candidate genetic markers for further analysis regarding management of KNP in order to fix SLA genotypes and differentiation of pig breeds. Consequently, this study characterizes KNPs using the SLA-6 gene and alleles and the variation of nucleotide sequences is also valuable for developing an SLA genotyping protocol. The results of SLA-6 SNPs of KNP reported here will serve as the reference study for KNP that can be used for the animal model based on requirements of gene fixation.

\section{ACKNOWLEDGEMENT}

This study contributes to internal project no. PJ010220. "Development of techniques and knowledge-database for applicable combination of genetic markers related to economic traits for Hanwoo and pig" and was supported by the National Institute of Animal Science in RDA.

\section{REFERENCES}

Ando, A., H. Kawata, A. Shigenari, T. Anzai and M. Ota, 2003. Genetic polymorphism of the swine major histocompatibility complex SLA. class I genes, SLA-6, -2 and -3. Immunogenetics, 55: 583-593. DOI: $10.1007 / \mathrm{s} 00251-003-0619-0$

Barbosa, A., O. Demeure, C. Urien, D. Milan and P. Chardon, 2004. A physical map of large segments of pig chromosome 7q11-q14, comparative analysis with human chromosome 6p21. Mamm. Genome., 15: 982-995. DOI: 10.1007/s00335004-3008-6

Chardon, P., C.R. Gaillard, L. Cattolico, S. Duprat and M. Vaiman et al., 2001. Sequence of the swine major histocompatibility complex region containing all non-classical class I genes. Tissue Antigens, 57: 55-65. DOI: 10.1034/j.13990039.2001.057001055.x

Charon, R., 2001. Narrative medicinea model for empathy reflection profession and trust. J. Am. Med. Assoc., 286: 1897-1902. DOI: 10.1001/jama.286.15.1897

Chung, H. Y. and S.H. Yoon, 2008. Sequence variation of the SLA-1 gene for korean native pigs. Genes Genom., 30: 507-514.

Chung, H.Y., M. McClure and J.Y. Kim, 2011. Phylogenetic analysis of the swine leukocyte antigen-2 gene for Korean native pigs. Genes Genom., 33: 345-351. DOI: 10.1007/s13258-0100112-8

Crew, M.D., B. Phanavanh and C.N.G. Borges, 2004. Sequence and mRNA Expression of nonclassical SLA class I genes SLA-7 and SLA-8. Immunogenetics, 56: 111-114. DOI: 10.1007/s00251-004-0676-Z

Ednaldo, S.F., H.S. Marcone, E.G.C. Jose, L.H. Maria and R.D. Marcia, 2012. Genetic characterization of bovine breed (TABAPUA) under artificial selection located in the amazon region. Am. J. Anim. Vet. Sci., 7: 226-232. DOI: 10.3844/ajavsp.2012.226.232

Ehrlich, R., R. Lifshitz, M.D. Pescovitz, S. Rudikoff and D.S. Singer, 1987. Tissue-specific expression and structure of a divergent member of a class I MHC gene family. J. Immunol., 139: 593-602.

Giovambattista, G., M.V. Ripoli, G.P. Peral and J.L. Bouzat, 2001. Indigenous domestic breeds as reservoirs of genetic diversity the argentinean creole cattle. Anim. Genet., 32: 240-247. DOI: 10.1046/j.1365-2052.2001.00774.x 
Keller, I., D. Bensasson and R.A. Nichols, 2007. Transitiontransversion bias is not universal, A counter example from grasshopper pseudogenes. PLoS Genet. 3: e22. DOI: 10.1371/journal.pgen.0030022

Kim, N.M., C.J. Woo, H.J. Choi, V. Ramu and S.J. Uhm et al., 2006. Discovery of single nucleotide polymorphisms in the SLA-6 cDNA from Korean native pigs and phylogenic analysis. Korean J. Genet., 28: 353-360.

Kim, T.H., K.S. Kim, C. BH, Y. DH and J. GW et al., 2005. Genetic structure of pig breeds from Korea and China Using microsatellite loci analysis. J. Anim. Sci., 83: 2255-2263. PMID: 16160034

Mallard, B.A., W. BN and K. BW, 1989. Influence of major histocompatibility genes on serum hemolytic complement activity in miniature swine. Am. J. Vet. Res., 50: 359-363. PMID: 2494914

Martens, G.W., J.K. Lunney, J.E. Baker and D.M. Smith, 2003. Rapid assignment of swine leukocyte antigen haplotypes in pedigreed herds using a polymerase chain reaction-based assay. Immunogenetics, 55: 395-401. DOI: 10.1007/s00251-003-0596-3

NRC, 2000. Nutrient Requirements of Cattle. 7th Edn., National Academy Press, Washinton, D.C., USA,

Park, K., H. Choi, L.M. Thong, O.J. Kwon and J.H. Kim et al., 2010. Simple and comprehensive SLA-DQB1 genotyping using genomic PCR and direct sequencing. Tissue Antigens, 76: 301-310. DOI: 10.1111/j.1399-0039.2010.01522.x

Rahman, M.A., S.M.M. Rahman, M.A. Jalil, S.N. Uddin and M.M. Rahman, 2006. Molecular characterization of black bengal and jamuna pari goat breeds by RAPD markers. Am. J. Anim. Vet. Sci., 1: 17-22. 10.3844/ajavsp.2006.17.22
Rothschild, M.F., H.L. Chen and L.L. Christian, L. WR, V. L et al., 1984. Breed and swine lymphocyte antigen haplotype differences in agglutination titers following vaccination with $\mathrm{B}$. bronchiseptica. J. Anim. Sci., 59: 643-649. PMID: 6490548

Shigenari, A., A. Ando and C. Renard, 2004. Nucleotide sequencing analysis of the swine 433$\mathrm{kb}$ genomic segment located between the nonclassical and classical SLA class I gene clusters. Immunogenetcs, 55: 695-704. DOI: 10.1007/s00251-003-0627-0

Smith, D.M., K.J.P. Lunney, G.W. Martens, A. Ando and J.H. Lee et al., 2004. Nomenclature for factors of the SLA class-I system. Tissue Antigens, 65: 136-149. DOI: 10.1111/j.13990039.2005.00337.x

Takezaki, N. and M. Nei, 1996. Genetic distances and reconsruction of phylogenic trees from microsatellite DNA. Geneti., 144: 389-399. PMID: 8878702

Yang, S.L., J.G. Wang, B. Liu, G.X. Zhang and S.H. Zhao et al., 2003. Genetic variation and relationships of eighteen Chinese indigenous pig breeds. Genet Select. Evolut., 35: 657-671. DOI: 10.1186/1297-9686-35-7-657

Zhang, G.X., Z.G. Wang, F.Z. Sun, W.S. Chen and G.Y. Yang et al., 2003. Genetic diversity of microsatellite loci in fifty-six Chinese native pig breeds. Acta Genet. Sinica, 30: 225-233. PMID: 12812088 